\title{
Configurações Urbanas e Função Socioambiental da Cidade: Análises Sintéticas em Araraquara-SP
}

\section{Urban Shapes and Social-Environmental Function of the City: Brief Analysis in Araraquara-SP}

\author{
Menzori, Ivan Damasco; Gonçalves, Luciana Márcia²; Kellner, Erich ${ }^{3}$ \\ 'Universidade Federal de São Carlos, Rodovia Washington Luis, km 235, \\ Programa de Pós-Graduação em Engenharia Urbana - São Carlos - SP- CEP: \\ 13565-905, Brasil, e-mail: menzori@ufscar.br \\ 2 Universidade Federal de São Carlos, e-mail: lucianamg@ufscar.br \\ 3 Universidade Federal de São Carlos, e-mail: erich.kellner@ufscar.br
}

\begin{abstract}
RESUMO
No Brasil, com o crescimento urbano fortemente atrelado a interesses econômicos, as práticas de produção de cidade revelam cenários que favorecem a reprodução do capital por meio da especulação imobiliária, em que o espraiamento urbano proporciona a criação de novas periferias urbanizadas, estendendo as fronteiras de mercantilização do território e, ao mesmo tempo, reservando terrenos bem localizados, vazios ou subutilizados, para extração de maisvalias urbanísticas. Nesta temática e contexto, busca-se identificar e evidenciar, por meio de dados e informações integrados em um Sistema de Informações Geográficas (SIG), os impactos socioambientais inerentes à dinâmica do crescimento urbano em Araraquara-SP. Os resultados apontam para um evidente ápice do espraiamento urbano na década de 1970, e uma tendência expansionista em direção às áreas de mananciais das bacias hidrográficas dos Ribeirões do Ouro e das Cruzes, enquanto lotes e glebas urbanos, maiores do que $1.000 \mathrm{~m}^{2}$ e dotados de centralidade, permanecem vazios ou subutilizados. Não obstante, a aplicação dos instrumentos do Estatuto da Cidade poderia mitigar este cenário de descumprimento da função social e ambiental da cidade, e incitar um crescimento urbano mais ordenado e sustentável.
\end{abstract}

Palavras-chave: expansão urbana, vazios urbanos, SIG.

\begin{abstract}
In Brazil, practices of city production reveal experiences with economic interests strongly linked to the dynamics of urban growth. The establishment of this scenario favored practices of capital reproduction through real estate speculation, in which urban sprawl provides the creation of new urbanized peripheries, which extend territorial and market boundaries, while reserving well-located, empty or underutilized urban voids to extract urban capital gains. In this context, the authors seek to identify and evidence, through data and information integrated in a Geographic Information System, the socio-environmental impacts inherent to the urban growth dynamics in Araraquara city. The results point to a clear apex of urban sprawl in the 1970s, and an expansionist trend towards the headwater catchments of Ribeirão do Ouro and
\end{abstract}

\footnotetext{
1 MENZORI, Ivan Damasco; GONÇALVES, Luciana Márcia; KELLNER, Erich. Configurações Urbanas e Função Socioambiental da Cidade: Análises Sintéticas em Araraquara-SP. In: II SIMPÓSIO NACIONAL DE GESTÃO E ENGENHARIA URBANA: SINGEURB, 2019, São Paulo. Anais... Porto Alegre: ANTAC, 2019.
} 
Ribeirão das Cruzes river basins, while urban lots and lands larger than $1,000 \mathrm{~m}^{2}$ and endowed with centrality remain empty or underutilized. Nevertheless, the application of the instruments of the City Statute could mitigate this scenario of social and environmental function, and incite a more orderly and sustainable urban growth.

Keywords: urban expansion, urban growth, GIS.

\section{INTRODUÇÃO}

No Brasil, a década de 1950 marcou o início de acentuadas mudanças no contexto urbano das cidades, em que a população urbana representava $36 \%$ do total nacional, passando para 45\% em 1960; e 56\% em algum momento da década de 1970 (GONÇALVES, 2010).

Este rápido crescimento urbano traduziu-se em cenários de aglomerações urbanas cada vez mais expandidas. Essa conjuntura exacerbou impactos que afetam diretamente o contexto de sustentabilidade ambiental urbana, representados por usos e ocupações ineficientes do solo, segregação socioespacial, problemas na mobilidade urbana e degradação ambiental (JENKS, 2004).

Na visão de Falcoski (1997), e de Mascaró e Bonatto (2013), esta dinâmica interferiu nos processos geohidrológicos naturais, agravando impactos ambientais relacionados à inundações, enchentes e deslizamentos, supressão de vegetação e ocupação em áreas de várzea, deteriorando serviços ecossistêmicos imprescindíveis.

Nesta temática e contexto, busca-se identificar e evidenciar, por meio de mapas georreferenciados, possíveis impactos socioambientais decorrentes da dinâmica do crescimento urbano em Araraquara - uma cidade média localizada no centro do Estado de São Paulo. A partir disso, são elencadas as Forças, Oportunidades, Fraquezas e Ameaças para uma gestão mais sustentável do espaço urbanizado.

\section{2 ÁREA, MATERIAIS E MÉTODOS}

\section{1 Área de Estudo}

Araraquara é uma cidade localizada na região central do Estado de São Paulo, a 270 km da

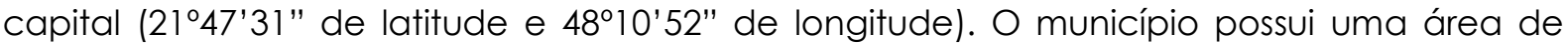
$1.003,625 \mathrm{~km}^{2}$ e uma população estimada em 230.770 (IBGE, 2017). Nas Figuras 1 e 2 está ilustrada a localização do município.

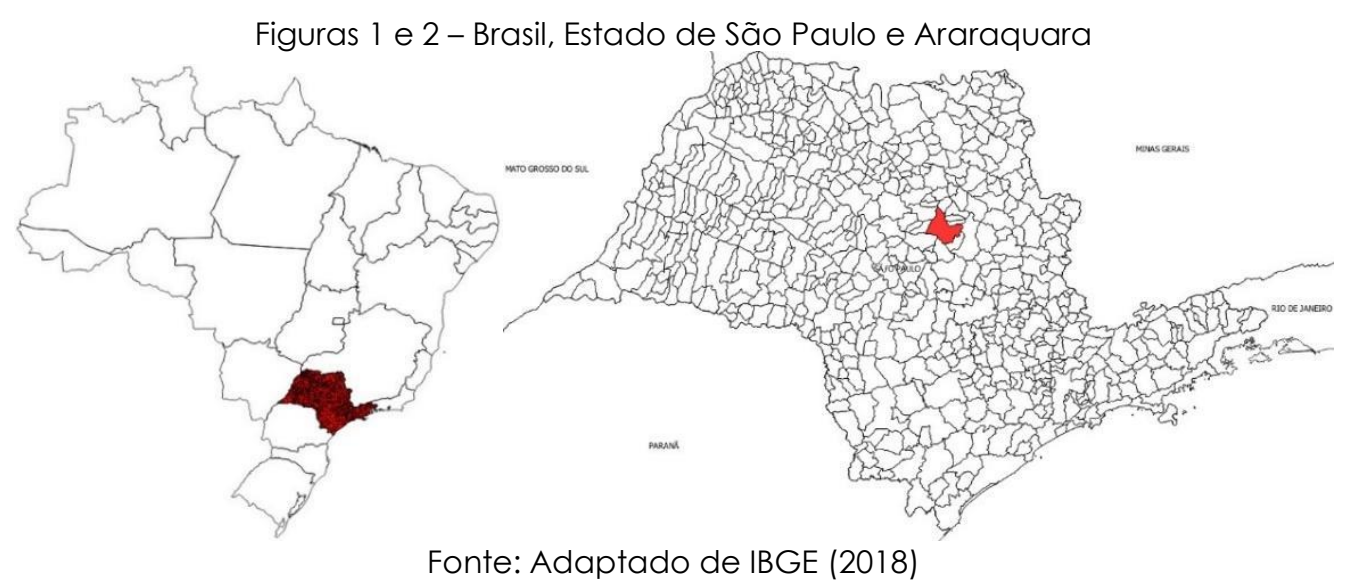

Desde meados do século XX, Araraquara incorpora a cultura de planejamento urbano, com a cidade apresentando uma profunda ligação histórico-cultural com o modelo do urbanismo moderno e culturalista das cidades-jardins, cuja identidade foi efetivamente consolidada por volta de 1930 (PERES, 2012). 


\subsection{Fundamentação Teórica}

Segundo Peres (2012), a evolução da ocupação do solo e os processos de formação econômica ocorreram simultaneamente em Araraquara, no início do século XX.

Foi a partir da década de 1950, quando a população urbana ultrapassou a rural, que Araraquara teve sua expansão e crescimento urbanos intensificados, por meio de processos formais ou ilegais que caracterizaram fortes estratégias especulativas de mercado (PERES, 2012). E foi durante a década de 1970 que o espraiamento urbano atingiu o seu ápice, em que a oferta de lotes produzidos superou a demanda de mercado e o crescimento populacional (GONÇALVES, 2010).

Para Silva (2013), tais impactos decorrem da ampla e decisiva influência do capital na produção social do espaço, com mercantilização da cidade. Esta conjuntura exacerbou impactos que afetam diretamente o contexto de sustentabilidade ambiental urbana, como as ocupações de áreas ambientalmente frágeis ou inaptas para urbanização, que se tornaram mais regra do que exceção no país (MARICATO, 2011).

Assim, o crescimento urbano associado aos interesses especulativos "[...] marcam profundamente a configuração espacial das cidades e contribuem sobremaneira para 0 agravamento dos principais problemas ambientais urbanos" (SILVA e TRAVASSOS, 2008, p.36).

\subsection{Materiais e Métodos}

O estudo foi estruturado em duas fases complementares: descritiva e analítica. Na fase descritiva, foram desenvolvidas as análises documentais e o georreferenciamento de produtos espaciais relevantes, em distintas escalas (GONÇALVES, 2010; PMA, 2005; 2006; 2014; 2017).

$\mathrm{Na}$ fase analítica, foram realizados os mapeamentos e análises geoespaciais, com representação dos resultados por meio de sínteses das principais Forças, Oportunidades, Fraquezas e Ameaças da atual configuração da malha urbana araraquarense, por meio de uma ferramenta de planejamento estratégico denominada análise sWOT2 (Strengths, Weakness, Opportunities and Threats).

Todos os dados espaciais foram integrados em Sistemas de Informações Geográficas (SIG), na Projeção Universal Transversa de Mercator (UTM), Datum SAD/69 fuso 22S, por meio do software QGIS, versão 2.18 (posteriormente atualizada para 3.0). A malha urbana foi importada em formato Drawing Exchange Format (dxf) a partir de PMA (2017), com coordenadas projetadas.

\section{RESULTADOS E DISCUSSÃO}

A partir dos dados de Gonçalves (2010) e PMA (2006; 2017), foram representadas as configurações da mancha urbana araraquarense, desde a década de 1960 até o ano 2017. como mostrado na Figura 3.

\footnotetext{
${ }^{2}$ A análise SWOT representa "[...] uma metodologia bastante conhecida internacionalmente, [...] [além] de [ser] uma técnica muito familiar aos gestores públicos [...]" (IPEA, 2018, p. 93). Como instrumento de planejamento urbano, permite analisar informações de maneira sistemática e estratégica, elencando os principais problemas e potencialidades do território observado.
} 
Figura 3 - Cenários da mancha urbana araraquarense por década

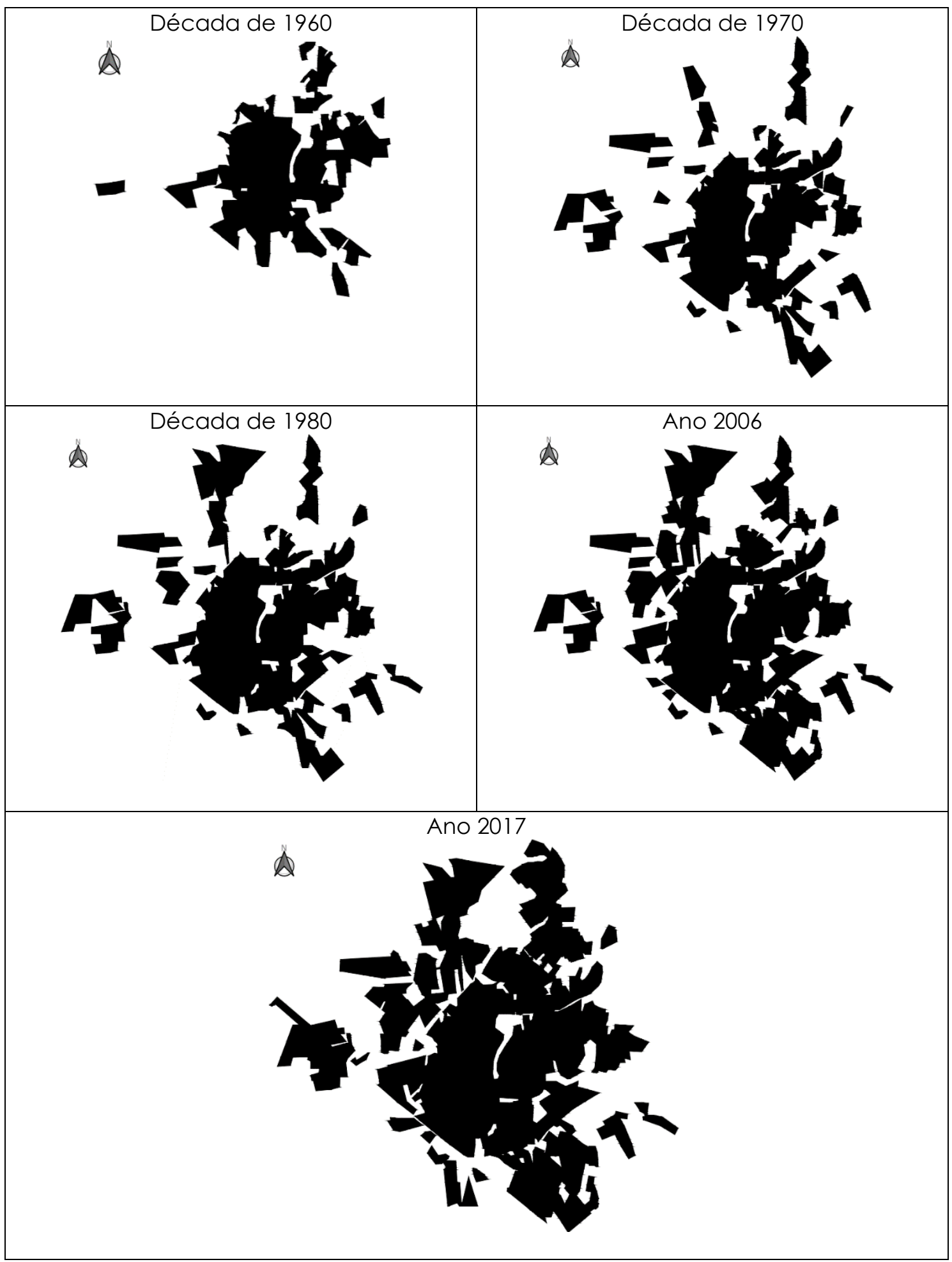

Fonte: Menzori (2018)

A partir disso, foram elaboradas sobreposições entre o cenário inicial estudado (década de 1960) e a situação atual (2017), com as principais bacias hidrográficas em que a mancha urbana está inserida (bacias do Ribeirão das Cruzes e Ribeirão do Ouro), como mostrado nas figuras 4 e 5 . 
Figura 4 - Mancha urbana na década de 1960 inserida nas bacias hidrográficas (a mancha branca no interior das bacias hidrográficas representa a ocupação do solo decorrente da evolução urbana)

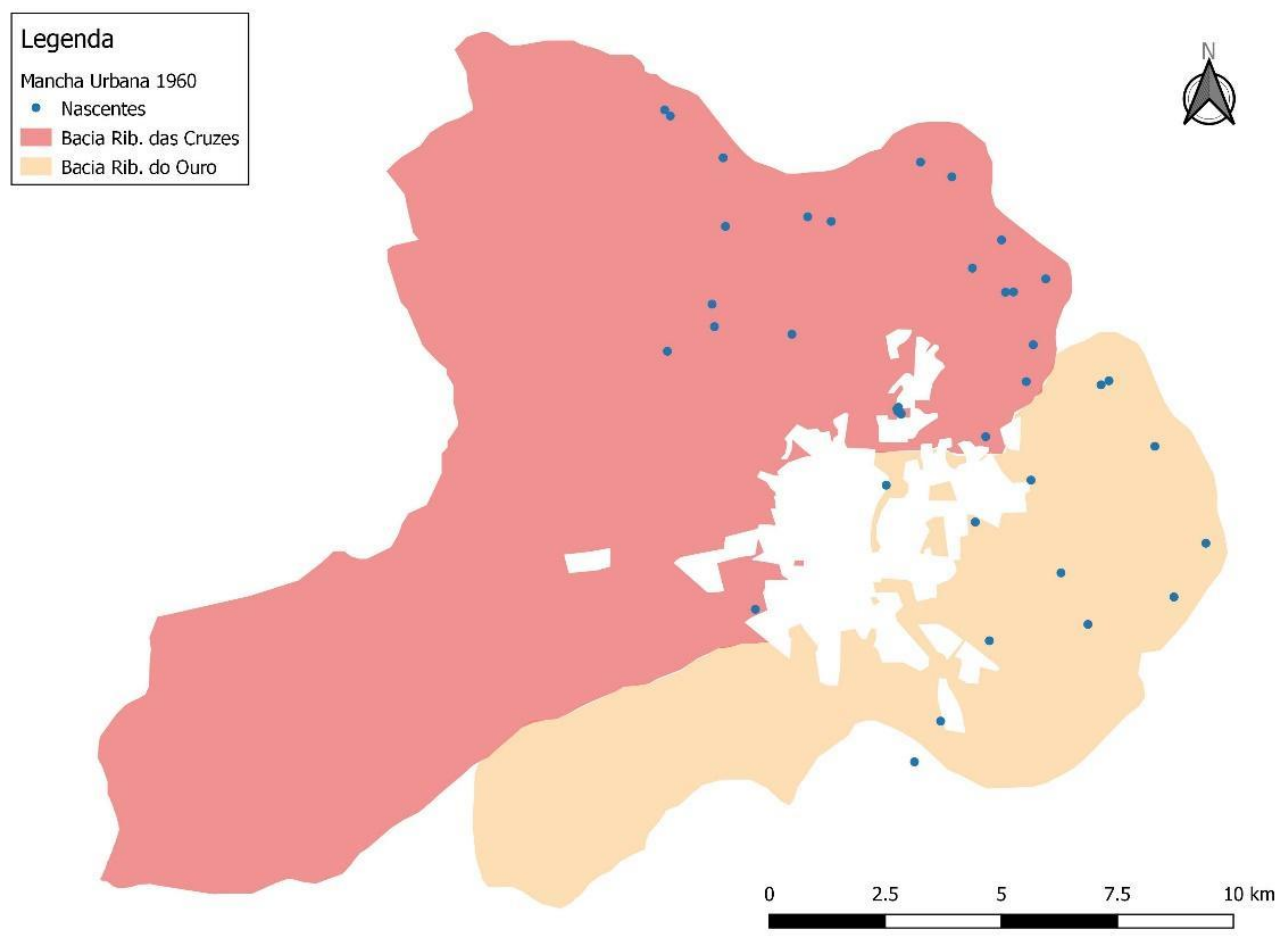

Fonte: adaptado de Menzori (2018)

Figura 5 - Mancha urbana na década de 2017 inserida nas bacias hidrográficas (a mancha branca no interior das bacias hidrográficas representa a ocupação do solo decorrente da evolução urbana)

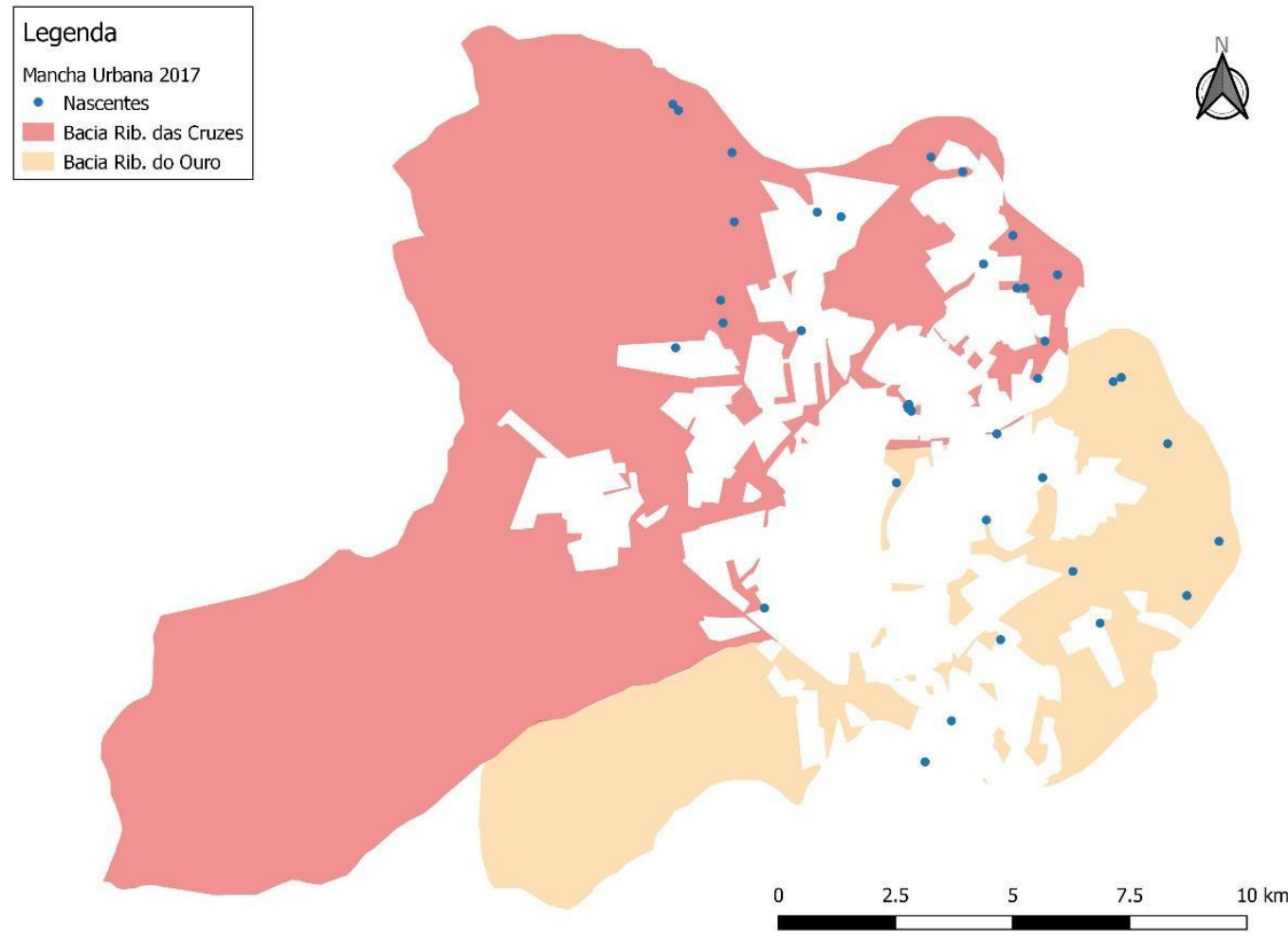

Fonte: Adaptado de Menzori (2018)

Considerando o cenário urbano consolidado na década de 1960 (primeiro avaliado nesta sessão), é perceptível que a inserção da mancha urbana incidia no divisor de águas entre as 
duas bacias, relativamente distante da maioria das nascentes de ambas as bacias (como mostrado na Figura 4).

Já no cenário atual, evidencia-se uma elevada ocupação do solo das bacias hidrográficas em direção às nascentes (extrema montante), representada por uma mancha urbana rarefeita em um vetor de expansão centrífuga, do núcleo para as periferias - conforme analogia de Falcoski (1997 e 2007).

Isso reforça o raciocínio de que a tendência de crescimento urbano em direção a áreas periféricas e até ambientalmente frágeis, antepôs interesses especulativos de mercado, em detrimento de um planejamento ambiental urbano mais ordenado e, consequentemente, sustentável.

Segundo Peres (2012), este modelo "[...] direcionou todo o processo de expansão urbana [...], construindo atrativos em áreas de importância socioeconômica, política ou de baixo valor econômico com o objetivo de transformá-las em áreas de interesse imobiliário". E Gonçalves (2010) eloquentemente explicita que as representações dos últimos 50 anos de evolução urbana mostram uma clara estratégia de expansão dos limites da urbanização.

Ademais, é perceptível que estes limites, estabelecidos há aproximadamente 40 anos atrás, abriram espaço para a implementação de estratégias de produção de cidade que avançaram em direção às áreas de cabeceira do Ribeirão das Cruzes e Ribeirão do Ouro, ao mesmo tempo em que criaram vazios urbanos mais bem localizados, dotados de centralidade urbana.

Isso porque, considerando apenas os vazios urbanos representados por lotes e glebas urbanos (PMA, 2017) maiores que $1.000 \mathrm{~m}^{2}$, e contíguos à malha urbana, o mapeamento preliminar aponta para uma estimativa de, pelo menos, 845 hectares vazios, sendo quase $65 \%$ desses constituídos por glebas maiores que $10.000 \mathrm{~m}^{2}$, como mostrado na Figura 6. 
Figura 6 - Vazios Urbanos maiores do que $1.000 \mathrm{~m}^{2}$

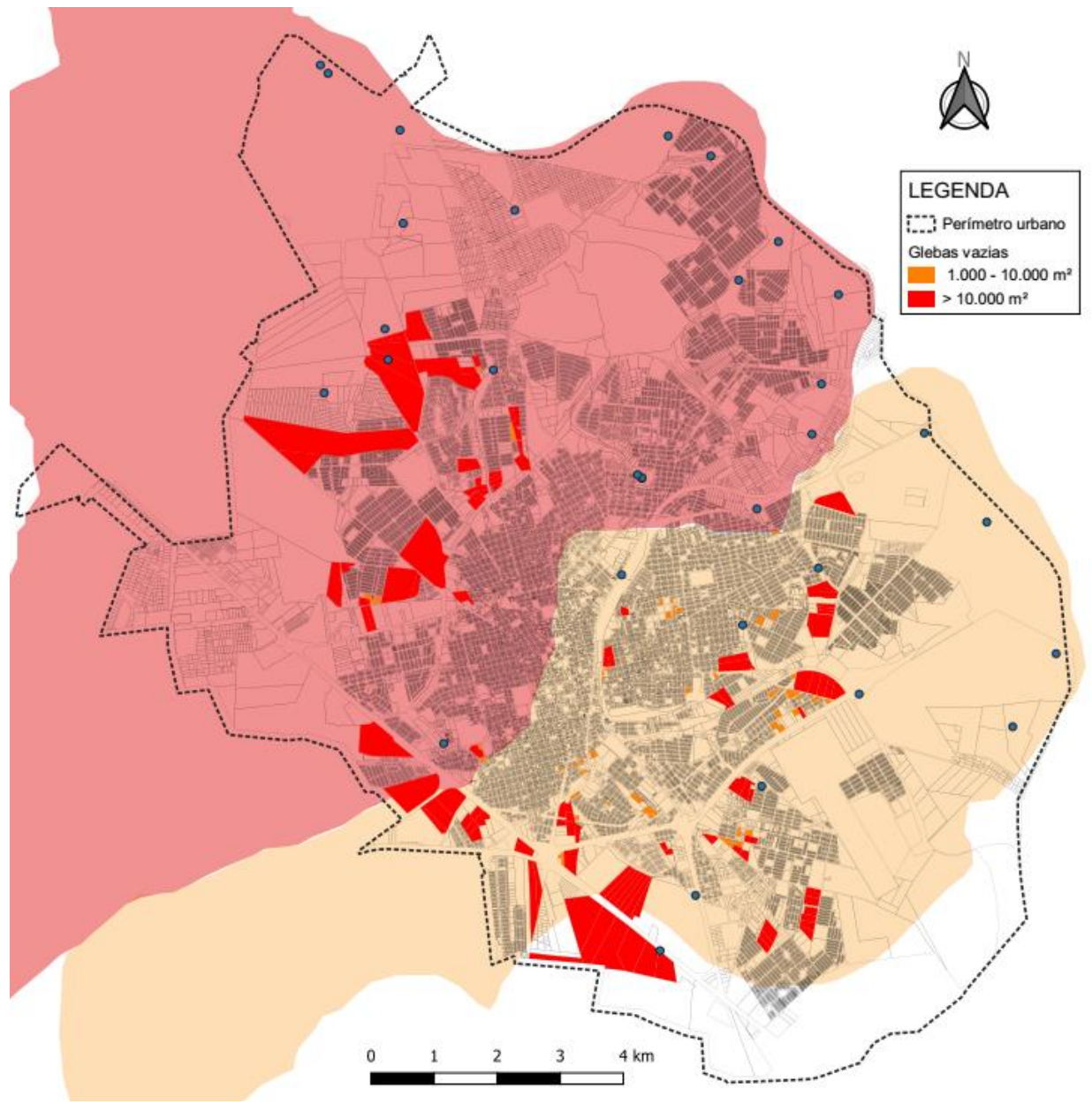

Fonte: Os autores (2019)

Para Maricato (2011), casos como este são recorrentes nas cidade brasileiras, sendo resultado de projetos atrelados ao interesse do capital imobiliário e da indústria automobilística, em detrimento da qualidade de vida, da conservação dos recursos naturais e do "direito à cidade3" - uma vez que representam estratégias de expansão das fronteiras de mercantilização do território urbano, afastando a população mais pobre para periferias e reservando vazios urbanos para extração de mais-valias urbanísticas.

Por fim, com o intuito de consolidar os resultados obtidos a partir das análises alçadas, no Quadro 1 são apresentadas sínteses da atual conjuntura do território urbano araraquarense.

\footnotetext{
${ }^{3}$ Anuente ao conceito presente em The Right to the City, descrito por Harvey (2008), no qual o direito à cidade excede a liberdade individual no acesso à recursos, e está relacionado ao exercício do poder coletivo.
} 


\section{REQUISITOS}

Crescimento urbano ordenado, bem localizado e sem manifestas criticidades ambientais

\begin{tabular}{|c|c|}
\hline FORÇAS & FRAQUEZAS \\
\hline $\begin{array}{c}\text { A Municipalidade detém base de dados } \\
\text { geoespaciais atualizada, que possibilita } \\
\text { identificar e delimitar os vazios urbanos no } \\
\text { cenário atual. A iminência de delimitação de } \\
\text { vazios urbanos como função social, por si só, } \\
\text { pode incitar a ocupação dos vazios urbanos } \\
\text { à priori da criação de novos bairros } \\
\text { periféricos }\end{array}$ & $\begin{array}{c}\text { Isenção dos proprietários de terras da } \\
\text { efetivação da função social (e ambiental) e } \\
\text { delimitação de limites expandidos para a } \\
\text { mancha urbana }\end{array}$ \\
\hline OPORTUNIDADES & AMEAÇAS \\
\hline $\begin{array}{c}\text { Incorporar os instrumentos do Estatuto da } \\
\text { Cidade na gestão dos vazios urbanos, para } \\
\text { (tentar) regular a influência decisória da } \\
\text { iniciativa imobiliária no planejamento urbano } \\
\text { e habitacional }\end{array}$ & $\begin{array}{c}\text { Agravamento da segregação socioespacial, } \\
\text { exclusão social e guetificação, isolando a } \\
\text { população de menor renda e } \\
\text { antagonizando a noção de direito à cidade. } \\
\text { Avanço da urbanização para áreas de } \\
\text { cabeceira, intensificando impactos } \\
\text { ambientais }\end{array}$ \\
\hline
\end{tabular}

Fonte: Os autores (2019)

\section{CONCLUSÕES}

São evidentes as influências do capital imobiliário na construção da cidade de Araraquara, em que a década de 1970 ficou marcada pela intensificação da fragmentação da malha urbana como estratégia especulativa. A expansão urbana produziu vazios que não incorporaram interesse do mercado durante décadas, e permaneceram retidos de maneira estratégica para a extração de mais-valias urbanísticas nos momentos oportunos.

Isso porque os cenários temporais, representativos da evolução urbana, evidenciam uma clara estratégia de expansão dos limites da urbanização em direção às áreas de cabeceira e, consequentemente, de reprodução do capital imobiliário sobre o território expandido, em que a década de 1970 representou um ápice no espraiamento urbano, que disseminou vazios urbanos que permaneceram reservados ao longo das décadas subsequentes.

Até mesmo no cenário atual, em que foram considerados, exclusivamente, os vazios urbanos maiores do que $1.000 \mathrm{~m}^{2}$, fica evidente o grande volume de terrenos subutilizados ou vazios remanescentes, contíguos à malha urbana, em contraposição à evidente expansão da região norte iniciada há cinco décadas - que poderia reafirmar a primazia de interesses especulativos atrelados à abertura de novas frentes de mercado (por meio da expansão urbana), em detrimento de um planejamento urbano mais ordenado e sustentável.

Em suma, é possível inferir que a dinâmica do crescimento urbano araraquarense, nos últimos anos, esteve fortemente ligada aos interesses econômicos do capital imobiliário, e à produção da cidade horizontal em extensão, de forma centrífuga (de dentro para fora). Esta manifesta liberalização do território negligenciou fatores inerentes à qualidade de vida dos cidadãos, comprometeu a conservação dos recursos naturais e favoreceu a degradação de espaços que, em tese, são especialmente protegidos por lei. 


\section{REFERÊNCIAS}

FALCOSKI, L.A.N. Dimensões morfológicas de desempenho: instrumentos urbanísticos de planejamento e desenho urbano. 1997.370p. Tese (doutorado) - Faculdade de Arquitetura e Urbanismo. Universidade de São Paulo.

Plano Diretor de Desenvolvimento Urbano Ambiental de Araraquara: instrumentos urbanísticos inovadores e agenda para uma cidade sustentável. In: PLANOS diretores municipaisnovos conceitos de planejamento territorial. São Paulo, AnnaBlume, 2007.

GONÇALVES, L. M. Quarto Congresso Luso-Brasileiro para o Planejamento Urbano, Regional, Integrado, Sustentável, 2010. Os vazios urbanos como elemento estruturador do planejamento urbano. Universidade do Algarve, Faro, Portugal. Disponível em:

http://pluris2010.civil.uminho.pt/Actas/PDF/Paper147.pdf . Acesso em: 09 dez. 2015.

HARVEY, D. The right to the city. New Left Review 53, p. 23 - 40. Setembro - Outubro de 2008.

INSTITUTO BRASILEIRO DE GEOGRAFIA E ESTATÍSTICA (IBGE). Brasil em síntese: Araraquara. 2017. Disponível em: https://cidades.ibge.gov.br/brasil/sp/araraquara/panorama. Acesso em: Jan/2018.

INSTITUTO DE PESQUISA ECONÔMICA APLICADA (IPEA). Desenho da política: modelo lógico, fundamentação e análise SWOT. In: Avaliação de Políticas Públicas Guia Prático de Análise Ex Ante. Brasília: Ipea, 2018.

JENKS, M. The Appropriateness of Compact City Concepts to Developing Countries. In: JENKS, M.; BURGESS, R. Compact Cities: Sustainable Urban Forms for Developing Countries. Londres: Taylor \& Francis, 2004. pp. 343-350.

MARICATO, E. Nono Congresso Nacional de Sindicatos de Engenheiros, 2011. A cidade sustentável. Federação Interestadual de Sindicato de Engenheiros, Porto Velho. Disponível em: < http://www.coptec.org.br/biblioteca/Agroecologia/Artigos/A\%20cidade\%20sustent\%Elvel\%20\%20Erminia\%20Maricato.pdf>. Acesso em: Ago/2016.

MASCARÓ, J.J.; BONATTO, D. do A. M. Infraestrutura Verde como Estratégia de Desenvolvimento Sustentável e Qualificação Urbana: Estudo de Caso da Cidade de Passo Fundo-RS. In: Encontro Latinoamericano de Edificações e Comunidades Sustentáveis. Curitiba. Anais...2013. pp. 1 - 10. Disponível em: http://www.bibliotekevirtual.org/simposios/ELECS2013/978-85-89478-40-3-a071.pdf. Acesso em: Dez/2017.

MENZORI, I. D. Dinâmicas territoriais e os corredores verdes como modelos de estruturação espacial urbana: abordagens inter-relacionais na cidade de Araraquara-SP. 2018. 230 p. Dissertação (Mestrado em Engenharia Urbana) - Centro de Ciências Exatas e de Tecnologia, Departamento de Engenharia Civil, Programa de Pós-Graduação em Engenharia Urbana, Universidade Federal de São Carlos, São Carlos, 2018.

PERES, R.B. O planejamento regional e urbano e a questão ambiental: análise da relação entre o plano de bacia hidrográfica Tietê-Jacaré e os planos diretores municipais de Araraquara e São Carlos, SP. 2012. 370f. Tese de Doutorado - Universidade Federal de São Carlos.

PREFEITURA MUNICIPAL DE ARARAQUARA (PMA). Lei Complementar $n^{\circ}$ 350, de 27 de dezembro de 2005, Plano Diretor de Desenvolvimento e Política Ambiental de Araraquara (PDDPA). 2005.

. Mapa da cidade. Secretaria Municipal de Desenvolvimento Urbano (SMDU), 2017. Disponível em: http://www3.araraquara.sp.gov.br/Pagina/Default.aspx?/DPagina=3972. Acesso em: Dez/2017.

Urbano, 2006

Mapa georreferenciado da malha urbana. Secretaria Municipal de Desenvolvimento 
. Mapas georreferenciados da hidrografia urbana, das APPs vegetadas e dos maciços urbanos de 2014. Secretaria Municipal do Meio Ambiente-SMMA, 2014.

SILVA, E. P. de P. e. A função social da propriedade urbana no contexto do desenvolvimento urbano sustentável. Dissertação (mestrado), Pontifícia Universidade Católica do Paraná. Curitiba, 2013. $158 \mathrm{f}$

SILVA, L. S.; TRAVASSOS, L. Problemas ambientais urbanos: desafio para a elaboração de políticas públicas integradas. PUC-SP, Cadernos Metrópole, n. 19, São Paulo, jan-jun 2008, pp. 27-47. 